\title{
Uncovering Metagovernance in Government- Third Sector Collaboration in Kano State, Nigeria
}

\author{
Abubakar Ali ${ }^{1,2 *}$ \\ Ahmad Martadha Mohamed ${ }^{3}$ \\ Mohd. Khairie Ahmad ${ }^{4}$ \\ ${ }^{1}$ Kano State Polytechnic, BUK Road, Kano State, Nigeria \\ ${ }^{2}$ Ghazali Shafie Graduate School of Government, \\ Universiti Utara Malaysia, 06010 UUM Sintok, \\ Kedah Darul Aman, Malaysia \\ ${ }^{3}$ School of Government, \\ Universiti Utara Malaysia, 06010 UUM Sintok, \\ Kedah Darul Aman, Malaysia \\ ${ }^{4}$ School of Multimedia Technology and Communication, \\ Universiti Utara Malaysia, 06010 UUM Sintok, \\ Kedah Darul Aman, Malaysia \\ "Corresponding author: aali052003@yahoo.com
}

\begin{abstract}
Uncovering metagovernance in collaborative settings in Kano state, Nigeria, is the main concern of this paper. The central question explored was, what were the governing frameworks used by government policy officials and third sector chief executives (CEOs) to metagovern collaboration in the resource constrained state? This question was explored using an interpretivist qualitative research design that involved in-depth interview sources and document analysis. The interviews consisted of a total of 12 participants, six government policy officials and six third sector chief executives, and, in each case, lasted an hour-and-the-half, in three cycles, over a period of three months. The interviews were analysed with the aid of NVivo-8 software as a data processing tool. The study findings suggest that although there was no standard framework for governing collaboration that could be described as systematic metagovernance, pragmatic combinations of a dominant 'dynamic approach' and an emerging 'stable approach' were employed to govern government-third sector collaboration in the state. Despite the limitations of this approach, it had prevailed in collaborative settings in the state for at least two decades and now urgently requires replacement. The paper concludes that for collaboration to be effective in delivering public services and publicly desired outcomes, key features of the dynamic and the stable approach to collaboration must be merged to co-create an innovative and resilient metagovernance system that will serve all actors involved in co-construction and co-creation activities in the state.
\end{abstract}


Keywords: Metagovernance, Government, Third Sector, Collaboration, Governing Framework

Received: 01/04/2020 Revised: 15/06/2020 Accepted: 25/06/2020 Published: 30/06/ 2020

\section{INTRODUCTION}

In most parts of the world today, government and third sector collaboration, have become generally accepted in principle and almost universal in practice. It seems that governments have come to terms with the fact that the third sector is a socially relevant partner in development management, almost as important as markets and public bureaucracies (Salamon, Sokolowski, Haddock, \& Tice, 2013). It is estimated that the third sector contributes significantly to the global economy (International Labour Organisation, 2011; United Nations, 2018). For instance, in Europe, where it is rapidly growing, it accounts for 13 percent of the workforce and provides full time employment to 28.3 million people across the continent (Enjolras, Salamon, Sivesind, \& Zimmer, 2018). In the United States, where it is relatively well developed, it contributed an estimated $\$ 985.4$ billion (or 5.4 percent of the gross domestic product (GDP) to the economy in 2015, with most of its giving (over 50 percent) going to religious, education and human services causes (Giving USA Foundation, 2019; McKeever, 2018, 2019).

While the contribution of the third sector to most economies of the developed and developing world is statistically murky (United Nations, 2018), the situation in Africa, and to a large extent, Nigeria, the continent's most populous state with about 200 million people, is even less clear (Ali \& Ghazali, 2020). However, contemporary government-third sector collaboration in the country is a recent development. It evolved out of a past that was associated with the struggle for inclusion and voice in public policy spearheaded by pro-democracy movements in the country during military rule in the 1980 s and 1990s (Kukah, 2001, 2013). Government-third sector interaction in this period was largely viewed as adversarial (Beckman, 2010), and only occasionally collaborative (Nigeria Network of NGOs, 2020), especially with pro-regime and, sometimes, moderate independent networks.

However, the last two decades have ushered in a stupendous rise in third sector growth throughout the country and the rest of Africa (Nega \& Schneider, 2014; Smith, 2010). With this upswing had emerged myriad challenges: managing proliferation, defining partnerships, service delivery, corruption, security, and corporate governance compliance regimes. In 
essence, the regulatory environment was in a state of flux. On the one hand, the Nigerian government sought to impose stringent controls (NGO Bill, 2016) on the third sector to curtail its growing influence in public policy and service delivery, while on the other the third sector was demanding for greater inclusion and less regulation to enable it operate more freely (International Center Nigeria, 2020). This seemingly irreconcilable dispositions - although recently addressed when the House of Representatives rejected the "bill to regulate civil society" entities in the country (Nigeria Network of NGOs, 2020) - revealed what all sides (government and third sector) recognised but could not agree on, which was the need for some form of metagovernance to deal with mounting problems of collaboration and service provision (Ali \& Ghazali, 2020).

Equally important was the realization that laws and mechanisms for governing collaboration in the country were relatively federal centred, opaque, non-standardised and sometimes informal rather than formal at state level. This impromptu situation, in the face of rising citizens' interest directly and indirectly shaping public policy, which made this study pertinent. This study was, therefore, an attempt to uncover the existing approach used to metagovern collaboration in Nigeria's most populous state, Kano, a land where secular based public service rules operated side-by-side with 'informal' Syariah law in the same bureaucracy; and where heterogeneous (secular and faith based) third sector actors were increasingly making inroads into what is predominantly a Muslim run public policy machinery; and, incidentally, where state policy officials and third sector chief executives (CEOs) respectively demanded for new frameworks to govern collaboration based on their self-interest.

With a population of over 20 million, Kano state has more people than any of the 36 federating units of the country, including the federal capital territory, Abuja, and all the ECOWAS member states individually. Historically, the state was an ancient trading route that drew people from throughout West, North and Central Africa combined with locals to form the melting pot that it is today (Usman, 2008), a centre of commerce, Islam, and rising third sector pressure on policymakers to deliver public goods and services efficiently.

\section{METAGOVERNANCE}

Metagovernance is used here to imply designing and managing public policy through composite styles, and norms drawn from hierarchies, networks, and markets for the accomplishment of societal goods (Agranoff \& McGuire, 
2003; Meuleman, 2008). This implies collaboration of self-regulating networks in ways that produce new governance norms that translates into regulatory improvements which co-governors can then employ to solve wicked problems. This practical form of network management involves sovereign actors allowing self-regulating actors to freely express themselves rather than imposing excessive constraints on the governance space to stifle actor conduct. In this sense, metagovernance is 'the regulation of selfregulation', it is about "how and to what extent it is possible for governors to regulate self-regulating networks" (Sørensen \& Torfing, 2007: 169) in their efforts to achieve socially desirable outputs and outcomes. In short, it is simply the 'governing of governing' (Bejakovic, 2019), or just the 'governance of governance' (Meuleman, 2019). This denotes the practical coordination of heterarchic network governance processes on the basis of norms of reciprocal interdependence.

Therefore, metagovernance is best understood by what is emphasised, that is, the type of collaborative processes involved in regulating self-regulation. The principal collaborative governors of metagovernance are typically government policy officials representing the state. Therefore, the state plays the leading role in metagovernance because it has the institutional, financial, and legal resources to do what markets and networks can barely accomplish without sovereign backing.

The leading role of the state is thus well recognised in network governance theory. In fact, metagovernance theory generally was an attempt to bring back the state into contention in network governance theory (Marsh, 2011). In the first account of this theory under poststructuralist influence, hierarchies were somehow 'fused' together with networks, since government was presumed to be a form of network in a pluricentric system under a disordered polity where metagovernors attempt to influence the third sector in desired directions. The second phase of the theory entails the critical realist perspective, which defines metagovernance as partnership (government plus governance) that takes place in the 'shadow of government' (Davies, 2012; Pedersen, Sehested, \& Sørensen, 2011). Here, government is treated as a principal partner and regulator of the metagovernance space. It exercises its power via hegemony in some Gramscian sense.

The third phase is couched in the Foucauldian perspective which assumed that 'threat and social control' are prevalent in governmental structures. In other words, 'governmentality', for Foucault (2010), was the defining 
concept that symbolised the state's desire to target and exercise control over the population, its welfare and its conduct through rationalisation of its actions and subtle cultivation of citizens' sense of self-governance to influence their involvement in their own subjection, thus furthering habits oriented to the 'conduct of conduct'. In metagovernance terms, this amounts to the use of technologies of agency (that is network actors employing techniques of knowledge and resources for self-transformation to attain quality self-regulation), and technologies of performance (as in compliance with governing standards and benchmarks) that disciplines the mind to self-conform rather than challenge power. This population centred form of governance was combined with economic, social and ideological forms of control exercised through 'governance at a distance' rather than through direct coercion (Bang, 2014; Dean, 2010; Chamberlain, 2014; Raffnsqe, Gudmand-Hoyer, \& Thaning, 2016; Rose, 1996).

The general idea in metagovernance theory was to make sense of the changing role of the state in a world of growing networks, decentred structures, and institutions. The main premise was that the logic of structures that had dominated conventional forms of public management was being replaced by the logic of flows in the governance of social life (Davies, 2012; Lash, 2002). The various metagovernance theories, as outlined by Sørensen \& Torfing (2007), were all attempts to capture this change, with each theory (interdependency, governability, integration, and governmentality) emphasising its own approach to the problem. Ultimately, we are left with no uniform ways of exercising metagovernance. Yet, the primary objective of metagovernance remains the same: conflict avoidance in situations of shared goal articulation, under realities that recognise the promise of metagovernance success and its likely failures. This paper operates largely within the interpretivist approach.

\section{METHODOLOGY}

The preferred type of study employed here is a qualitative research methodology (Coffey, 2018; Flick, 2018; Merriam \& Grenier, 2019). This was considered suitable for uncovering approaches adopted by government policy officials and third sector chief executives (CEOs) to metagovern collaboration in resource constrained Kano state. This problem was explored using a qualitative research design that involved in-depth interviews, guided by semi-structured questionnaire, as the primary data source, with document 
analysis being supplementary. The documents analysed included official government and third sector records such as transaction letters, memorandum of understandings, and agreements covering joint projects of various shades implemented in Kano state in the last two decades; and extant literature on government-third sector collaboration from databases using keywords to source relevant articles, especially recent works connected with the main subject of this research.

\section{Study Participants and Data Collection}

This study focused on uncovering metagovernance approaches in collaborative settings in Kano state that involved the following participants: (i) government policy officials, elected and professional; and (ii) third sector CEOs encompassing secular and religious, male and female participants, who led networks that collaborated with the Kano state government in cocreation and co-production activities in the state. However, the majority of government and third sector policy actors were men. Therefore, in both categories of participants (12 in all), the female presence (only three) was small, reflecting male domination of policy organs in public life in the state. All the participants were anonymized using appropriate ethical pseudonyms.

The government and third sector participants purposefully selected for this study were those directly involved in, and were knowledgeable about, collaborative activities in the state, with at least two years' experience in joint policymaking. For each category, we purposefully selected participants who were likely to supply full depiction of collaborative governance as they experienced it within the last two decades. The 12 participants in the study were divided into a group of six each side, government and the third sector. The number of individual interviews conducted in each group was decided by saturation. For each participant, however, the interview lasted about an hour-and-the-half per cycle. In all a maximum of three and a minimum of two cycles (Brinkman \& Kvale, 2018) of interviews were conducted with each participant to capture their perspectives on metagovernance of collaboration in Kano state. Most interviews were held in the offices of the participants over a period of three months. The goal was to arrive at a thick description of the phenomenon.

Kano metropolis was chosen for this study because it was the seat of government and the most heterogeneous part of the state, from where diverse formal third sector chief executives (CEOs) collaborated with state policy 
officials' in co-constructing policies and delivering services, thereby yielding rich assorted data. The population of Kano as a state, and the diversity of its capital in political, cultural, economic and demographic terms, made it ideal for capturing the range of data that reflected the varied perspectives available in government-third sector collaboration in the state. These characteristics laid bare the context of the study.

\section{Data Analysis}

All interviews were transcribed verbatim using the recommended secretarial method (Howitt, 2016). The interviews were analysed with the aid of the NVivo software. The analysis approach relied on constant comparison as suggested by Corbin and Strauss (2015). Here, a three stage coding process was employed: The first involved open coding in which key portions of the interview data relating to the research question was identified and put together as related concepts, depicting aspects of a participant's perspective on the study phenomenon. The second stage consisted of a form of axial coding that brought together relevant parts of the data under a shared theme that reflected the participant's views. This process was followed to treat the interview transcript of each participant until all 12 were completed. Next, all the transcripts were then compared to arrive at a composite picture of themes, including an overarching theme, which depicted the study findings. This entire process was recursive. It involved moving forwards and backwards throughout the data, comparing aspects of it to be sure of its relevance in answering the research question. Overall, the data was displayed in the form of quotes and narratives rather than visuals (Grbich, 2013).

\section{FINDINGS}

Analysis of the in-depth interview data from government policy officials and third sector CEOs resulted in our identifying two broad perspectives on governing frameworks used to metagovern collaboration in Kano state: The 'dynamic approach' and the 'stable approach'. The dynamic approach entailed delineation of 'stakeholder interest', 'ad hoc arrangements', and 'shared vision'; while the stable approach comprised attempts by participants to articulate lasting features of collaboration such as, 'identity and coordinating standards', and 'institution building'. Thus, the overarching theme participants identified here was 'governing framework'. This was linked with two attached themes as separate branches that were labelled 
the 'dynamic approach' and the 'stable approach' to metagovernance of collaboration. Each of these is subsequently addressed in the narratives that follow.

\section{Governing Framework}

\section{Dynamic Approach}

The dynamic approach participants frequently referred to in their collaborative experiences consisted of three elements: 'stakeholder interest', 'ad hoc arrangements', and 'shared vision'. Collectively, these describe active themes that were generally fluid and unstable, and usually surfaced in governmentthird sector collaboration.

The first 'dynamic approach' theme participants in this inquiry were concerned with was 'stakeholder interest'. This mostly had to do with how competing actors defined, negotiated, and integrated their immediate interests into the collaborative process. Therefore, the dynamic governing framework was shaped to accommodate such interests.

Asusu, a high ranking policy advice official, was quick to layout areas he deemed as 'stakeholder interests' under the dynamic framework of collaboration. For him, as for most government policy officials, the thorny issues centred on 'the need to know' certain things in advance before actually engaging with the third sector.

"We should look at the contribution that is coming in. We have to know it", he emphasised.

These include issues such as data management, finance, human resources, project impact, monitoring and evaluation.

Government policy officials repeatedly mentioned these issues as representing 'stakeholder interests' in collaborative settings.

A third sector participant pointed out that under the dynamic approach to collaboration, stakeholder interests were 'generously' taken care of through incentives embedded in the engagement process. Therefore, government policy officials were usually 'motivated' to engage. Asked what the participant, a key faith based influencer, meant by "motivation" in this context, Na Allah replied, 
"Motivation can mean money, inducement, encouraging words, and things like that. Without it, collaboration will be impossible in our environment".

Another participant, Karkara, a ranking law maker, stressed moral values as part of what held stakeholders together in the collaborative process. These values, Karkara thought, were essential to his personal involvement in boundary spanning activities, and ought to feature in any formal construction of a standard governing framework to guide collaboration in the state.

"If the NGOs come they have to respect our religion, tradition and dignity as a community. If they clash with these values then we say, 'no' ", stated Karkara.

This talk about religion, tradition, and community dignity ran throughout participants' description of 'stakeholder interests', suggesting that both government and third sector actors felt strongly about the subject.

In addition, there were participants who called for "the interests of civil servants in the state" to be factored into any governing framework meant to formally metagovern collaboration. As Malama, a permanent secretary, calmly but firmly stated, "We will like to see a framework that involve civil servants in projects."

Further, Bature, a representative of international third sector interests, admonished the local third sector CEOs by saying, "Don't be confrontational" in approaching government policy officials; insisting that there ought to be 'consent' before the third sector enters any community to implement a project. "NGOs should not just come and start doing work without identifying the entry points."

The question then is: who really are the stakeholders where collaboration is concerned? The government? Third sector actors? Community gatekeepers? Service users? Or, all of these parties combined? The dynamic approach to collaboration only provided partial answers to these questions.

What the second dynamic approach theme, 'ad hoc arrangement', revealed, however, were three interesting perspectives about how collaboration was governed in the last two decades.

The first perspective suggested categorically that there was 'no' standard governing framework that guided collaboration. The second perspective was 
more ambivalent, as participants were not sure of whether or not there was a standard framework. The third perspective anchored itself on documents such as the military era edict on self-help groups, and project related financial guidelines, terms of reference (TOR), and memorandum of understanding (MOU) to imply that some working governing framework existed to metagovern collaboration. Even those who offered the latter perspectives had to acknowledge that, "We have to develop proper legislation to give the third sector stronger legal backing if we believe they are important to our development", stated Sa'adatu, a leading third sector executive in the state.

As for the third dynamic approach theme, 'shared vision', it described the co-construction of 'strategic priorities' for the common good. Participants in this study expressed their concerns about 'shared vision' when they talked about the lackadaisical attitude of policy officials towards strategic goals in collaboration. For these participants, constructing a shared vision was deemed a major challenge in the collaborative process. Boko, for instance, expressed deep unease over the sheer 'vision deficit' of government policy actors as regards engaging and constructing shared vision with the third sector. The participant complained that, "You hardly hear any policy maker stating that this is a sector that they need to collaborate with in the drive towards transforming the country. This non-recognition by the state is contributing to the problem of designing a shared vision".

Contrary to what Boko thought, however, some government policy officials related their attempts to work on a shared vision with third sector CEOs, especially in the rural areas. Adali, a participant with vast policy experience at trisector levels, and one time chair of the state executive council, said that where shared vision was concerned government took note of two factors: the registration status of the third sector body, and its mission or "areas of operation".

Adali clarified his thoughts this way, "We tried to lead international NGOs to where their support can be useful, in health, education and services". He went on, "we set out certain standards" for the informal community based organisations (CBOs) rather than the mainstream NGOs.

The standards required that the third sector body be 'rural based, democratically led, with a written constitution that was consistent with community aspirations', before the ministry issued a recognition certificate. And to fully ensure compatibility of vision, entities with similar objectives 
were "brought together to form a bigger body." This approach of government policy officials to 'guide' third sector vision seemed serendipitous, in the sense that the newly established office for NGO affairs was, "gradually discovering ways and means of operating", said Adali.

To sum up the picture on the 'dynamic approach' theme under the main theme of governing framework for metagoverning collaboration between government and third sector policy actors in Kano state, we found that an overwhelming number of participants stated that there was no standard governing framework that guided their collaboration in the public policy process. Further, participants totally agreed that collaboration was approached through ad-hoc arrangements. In addition, slightly more than half of all the participants indicated that deference to stakeholder interests was central to their collaboration; while a few others still held that collaboration was governed by shared vision as narrowly defined by the parties for a given purpose.

These perspectives tell us that there were shifting concerns and loyalties throughout the collaborative process. This, however, does not tell us why the 'dynamic approach' (especially, ad hoc arrangements) persisted in the face of alternative ways of governing collaboration. What was clear was that the 'dynamic approach' operated side-by-side with attempts to construct a more stable approach to metagovern the collaborative process. Participants shed light on these issues when they unveiled their experiences on the 'stable approach' to collaboration.

\section{Stable Approach}

The stable approach refers to an approach to governing collaboration that was based on a systematic process that involved defining corporate identities and setting standards (rules and regulations) for the construction of an enduring institution. This can be seen in participants' references to "frameworks", "standards", "coordination", "rules and regulations", "procedures", "laws", "guides", and related concepts that are basically entwined with efforts to build lasting structures. Stable elements in collaborative settings are therefore tied to some kind of Weberian thinking about quality, merit, legacy, order and stability, so as to avoid arbitrariness and needless disorder.

Participants voiced their views on the 'stable approach' theme when they talked of, 'identity and coordinating standards' and 'institution building' for collaboration between government policy officials and third sector CEOs. 
Karkara, for instance, outlined what he felt were key 'identity' issues for the third sector to clarify if it must fully engage with government in the policy process: "First, where is the NGO from? What are its core principles, mission, or vision? What are its objectives? What are its rules and regulations?" Once these issues are clarified in the context of their consistency and conformity with "Laws specific to Kano state, which entails religion, and federal laws", then, collaboration can proceed.

An alternative perspective on the identity question was posed by Bature and Boko. Both participants were of the view that defining the third sector should be the first step towards governing collaboration through standards.

As it existed, "It was difficult to determine who the true third sector actors were", stated Bature.

For Boko, the crux of the matter was the image of the third sector, which can be saved, "If we retrench fraudulent NGOs", through demarcating proper boundaries of conduct for members.

In addition, majority of the participants proposed that third sector dependence on foreign support be drastically reduced by way of government "grant" to the local third sector. They wanted this to be made mandatory in any coordinating standards co-constructed for collaboration.

Yaro was, however, more critical in his views on standards setting, stressing the need to certify and benchmark third sector performance. "Actually, we need to get value for money", Yaro emphasised. Many public managers felt the same way on this matter.

Another aspect of the coordinating standards that attracted the attention of participants was the modalities for constructing the framework. Here most participants favoured the co-construction approach. But, Doka, a policy adviser in government legal department, opted for a "consultative approach" in which government will invite third sector CEOs and relevant ministerial inputs, and then proceed to "Draft the law following the normal procedure for drafting a bill."

Some participants raised fears that imposing a uniform governing framework in this manner might obscure ministerial peculiarities, unlike 'ad hoc arrangements' that were perceived as suited to agency needs. These differences 
drew attention to the tensions between special needs and uniform standards in the attempt to employ stable frameworks to govern collaboration.

The summation of participants' perspectives on the use of 'identity and coordinating standards' as frameworks for stabilising collaborative governance suggested that third sector identity was still an unresolved issue amongst government officials and third sector executives. Moreover, the idea of approaching collaboration through governing standards was accepted by most participants, especially government policy officials. For third sector executives, however, there were concerns regarding freedom of expression and operation. Nonetheless, majority of the participants were hopeful that resolving the identity and coordinating standards issue might bring about greater stability to collaboration and metagovernance generally.

The next stable approach to governing collaboration was perceived by participants as, 'institution building.' This describes an approach to collaboration that was driven by a deliberate and systematic effort to make it more permanent through agencification. That is, establishment of an autonomous body that will govern the common affairs of cross sector actors.

Participants approached 'institution building' from a variety of perspectives. Some talked about it as, "setting up a directorate", or "creating a bureau", with full powers to handle government-third sector collaboration issues. Others used concepts such as "strengthening local network capacity", "actor sensitisation", and "need for project implementation" as justification for institutionalising collaboration. For example, Bature commented that, "There was need for one agency in government that will be coordinating the activities of the third sector".

Other participant stated that multiple government agencies were responsible for coordinating third sector activities, with each having its terms and conditions for doing so.

Adali suggested that, "Establishing a single agency will make NGOs function as a bridge between government and the masses, conveying government's agenda, and working as its policy sounding board for effective social control."

However, there were other participants' whose perspective on institution building was slightly different. These participants emphasised social 
purpose rather than the 'surrogate' factor for institution building. The idea was that government could use the third sector chiefly for innovative project implementation, just like it is done in the developed countries; and for research purpose as well, since ministries have failed to effectively utilise their 'departments of planning, research and statistics' for its declared objectives.

Finally, a few of these same participants mentioned the State Education Sector Project (SESP) as a model of what collaboration can accomplish in the state. Under the SESP, hierarchies, markets, and networks collaborated to deliver services, unlike the conventional ministerial contracts system where, "Only private contractors' implement government projects", stated Amana.

Despite differences in what seemed contradictory motives for wanting to build permanent institutions to govern collaboration, participants generally agreed that this approach offered the best opportunity for stability and permanence in metagovernance. Therefore, the stable approach to governing collaboration, although emergent, gave most participants hope that if fully institutionalised, might positively change the future of collaboration in the state. While less than half of all the participants commented on 'institution building' and the 'stable approach' to collaboration, their views manifested the concerns of the majority around standardising co-governance mechanisms for better service delivery in the state.

The core finding here is that the overwhelming majority of the participants indicated that collaboration had been based on pragmatism anchored largely on the dynamic approach, as there was no standard governing framework to guide the process and guarantee stability. Yet, a few of these same participants cited ongoing government efforts to construct a stable framework as a threat to collaboration, as it might be used to adversely regulate third sector conduct. The majority of participants indicated that in the absence of a standard governing framework to guide collaboration, ad-hoc arrangements prevailed. This dynamic approach, although imperfect, was deemed realistic by most participants. Yet, these same participants generally expressed a preference for the stable approach towards collaborative governance.

\section{DISCUSSION}

Having interviewed and dissected documentary sources on collaborative activities between government policy officials and third sector chief 
executives, we uncovered two major approaches that governed collaboration in the policy process in Kano state. These approaches were identified as the 'dynamic approach' and the 'stable approach'.

The study findings can therefore be summed up by saying that there was, first, the predominance of the dynamic over the stable approach to collaboration. Second, that there was absence of standard governing framework to guide actor conduct in collaborative settings. Third, there were emerging efforts, mostly driven by government policy officials, to standardise collaboration so as to make it more effective and lasting. Then there was the fear factor, expressed by a few participants who thought that introduction of a standard governing framework might be used to adversely regulate third sector conduct.

It is significant to note, however, that the two broad approaches to governing collaboration uncovered by the study, the 'dynamic approach' and the 'stable approach', seemed to traverse the same broad continuum. In essence, they were consistent with the wider regulation, co-production, co-creation, and governance literature (Brandsen, Steen, \& Verschuere, 2018; Sørensen, 2014) that associated government regulatory conduct with attempts to secure and stabilise modes of governance for capitalist development (Jessop in Bevir, $2007_{\mathrm{a}}$ ), and create subtle norms of conformity as envisaged in Foucault's govenmentality (Burchell, Gordon, \& Miller, 1991).

The 'dynamic approach' represented the early stages of collaboration, while the 'stable approach' reflected qualities associated with laterstages of collaboration where actor roles are more clearly defined and governing frameworks more standardised as recognised mechanisms for metagovernance. Thus, both the dynamic and stable approaches participants described were suggested in the literature (Jessop in Bevir, 2007.: 233; Milward, 2015: 217-218) as meaning making and values transmission mechanisms that were indicative of "some conditions for effective governance" and elements of "design principles" for good results in governance. In this sense, they symbolized both the technologies of agency and technologies of performance at work.

\section{Analytic Categories}

We developed two analytic categories to capture and reflect the two broad approaches to governing collaboration as reported by the participants. The first analytic category we labelled, "Dynamism without Stability." The second 
analytic category we named, "Stability through Innovative Metagovernance." Both categories are interlinked and discussed as follows.

\section{Dynamism without Stability}

The recurring themes where the dynamic approach to governing collaboration was concerned appeared to be three. The first was defining 'stakeholder interest'; the second was constructing a 'shared vision' in the face of competing policy outlooks between typically third sector executives and government policy officials. The third question had to do with the use of 'ad hoc arrangements' to facilitate collaboration.

Usually, government policy officials perceived of themselves as both "stakeholders and gatekeepers." Whereas third sector CEOs designated themselves as "community stakeholders". In this sense, they seemed to assume an 'unelected representative' role for themselves in public policy. For Nadia, this was necessary because, "When the law makers are bought over by the government, we NGOs become the alternative voice."

But the main complaint from both sides, the evidence shows, was about "transparency." Government policy actors repeatedly charged that third sector chief executives were "not forthcoming about their budgets", or their full package of commitment to the government in terms of, say, resource commitment, data management, capacity building or monitoring and evaluation. Here, it seemed, while government policy officials were thinking and acting in terms of regime life cycle (4-8 years), third sector CEOs were doing the same thing, but in terms of project life cycle (usually 1-3 years). Therefore, both sides, it appeared, were self-centred and unable to reconcile these differences. Consequently, complaint about non-transparency and poor accountability persisted. This was not unusual in collaborative settings where corruption had become an inveterate problem (Smith, 2012; 2010).

A similar perspective was expressed when participants talked about the construction of 'shared vision', to facilitate collaboration. Agenda setting and intervention domains seemed to be the main bone of contention here. Beneath this veneer, however, there was what can be described as 'philosophical nuances' in vision, where heterogeneous secular oriented local third sector CEOs tended to tilt policy initiatives towards secular ideas reflecting 'partner' preferences, while government policy officials tended to opt for seemingly 'religious policy outlooks' to arouse ummah (Islamic community) 
support. These 'vision differences' had manifested themselves in issue areas that included girl child education, child rights, women's rights, and gender and sexuality matters generally. The literature suggests that these questions were not unusual in predominantly Muslim societies (Abbas \& Hamid, 2019; Mazrui, 2012; Ruby, 2019), which partly explain why Kano was viewed by many 'partners' as "highly sensitive and volatile" where collaboration was concerned. Bature suggested that "To succeed in collaboration in Kano is to succeed anywhere else in Nigeria".

Another aspect of shared vision and stakeholder interest that participants found disturbing was election related policy shifts. Typically this had to do with an outgoing administration being replaced by an incoming one. This transition period is usually replete with uncertainty in relations between third sector CEOs and newly appointed policy officials. Where the bureaucratic machinery is weak and the higher civil service heavily politicised, policy instability becomes the order of the day. Anonymity, neutrality and professionalism are compromised. Therefore, policy advice officials were typically unable to sell 'continuity in collaboration' to incoming policymakers. For this reason, collaborative projects were usually tied to regime lifespan to avoid abrupt cancellation or abandonment under a new administration.

The third theme in the dynamic approach that participants were concerned with was 'ad hoc arrangement.' This component of the dynamic approach to governing collaboration received far more attention in participants' narrative than the 'stakeholder interest' and 'shared vision' themes combined.

From the perspective of an overwhelming number of government policy executives, ad hoc arrangement problems in collaboration were mostly third sector related: its classification and identity, its registration and funding profile, its board membership, organisational form, transparency, and accountability, and even its disparate roles and ever-changing agenda, right down to its turnover, all were matters deemed necessary for serious scrutiny if collaboration was to be effective.

Government policy officials largely associated these problems with what they perceived as the absence of standard governing framework to metagovern collaboration. Despite this absence of governing standards, collaboration proceeded on ad hoc basis with tools such as MOUs, terms of reference (TOR), financial guidelines, and, "reporting formats and reporting templates", said Amana. 
The reporting format referred to periodic reports that engaged third sector actors had to submit (monthly, quarterly as agreed) each time they completed a defined phase of an assignment. It was usually part of the agreement or TOR that third sector service providers had to comply with. The aim, basically, was to ensure rule based ethical conduct (transparency/accountability) and effective service delivery.

The main question to ask, in the light of the assorted problems associated with the ad hoc approach to collaboration was, why did it persist despite government policy officials repeated claims of preference for uniform governing standards to manage collaboration? A preference that they shared with a few third sector chief executives with close ties to the higher bureaucracy. The apparent reason appears to be what we already mentioned earlier regarding the benefits of the dynamic approach to collaboration: flexibility, convenience, and innovation.

Despite these seeming benefits of the ad hoc arrangement, many participants insisted that its cost outweighed its benefits. Participants reasoned that it was often arbitrary and allowed little or no room for strategic thinking or planning for efficient collaboration. In fact, it was deemed so unstable that any party can opt out of, or abandon, projects as they please without due consideration given to the implications on service users or the targeted community. Being ad hoc, after all, implied little pre-planning, pressing need, and quick action taken for a specific purpose.

As Doka reasoned, "Government can engage with an NGO or development partner to do a project for a year or two and then leave without any consideration for sustainability."

A few of the participants who expressed strong opposition to the ad hoc arrangement extended their criticism to the entire dynamic approach, which they viewed as corrupt, malfeasance prone; unpredictable, averse to long term planning and proper metagovernance. This state of affairs, the participants' assumed, made the ad hoc arrangement and the entire dynamic approach to collaboration to persist.

Nadia, in particular, heaped the blame on government policy officials when she said, "They like it this way because there is confusion, no proper rules of engagement. Each ministry takes advantage of the situation to make money." This seeming vacuum, the participant felt, was being exploited by government policy officials steep in 'self-service.' 
Amidst these complex ad hoc arrangement challenges, some third sector participants, like their government counterparts, felt that it was time to craft a standard governing framework to metagovern collaboration. This desire it seems was primarily driven by the need to attract budgetary support to the third sector for execution of community level projects, while leaving aside issues of network proliferation, intervention, performance, transparency, and accountability as secondary.

For Sa'adatu, what is to be asked here is this: "Why insist on imposing governing standards? Who and who will be involved in writing the governing framework?" This question hints at Castells $(2007 ; 2011)$ proposition on power in network arrangements, as those who determine 'the rules of inclusion and exclusion' typically determine the collaborative boundary. That is, they set the rules of engagement, the terms and conditions, the governing framework for metagovernance. This brings us to the second category for analysis.

\section{Stability through Innovative Metagovernance}

For those participants seeking what they viewed as stability and order in collaboration, constructing standard governing framework was simply a matter of necessity in a resource challenged setting such as Kano. Introducing a uniform governing standard, they reasoned, will accomplish two things: weed out fraudulent third sector actors whom they felt were giving voluntary work a bad name; and provide a platform for order, stability, predictability, and quality permanence in collaboration generally.

Furthermore, most participants who favoured the stable approach saw registration with the corporate affairs commission (CAC) and relevant state agencies as inadequate to overcome the instability they associated with the dominant dynamic approach to collaboration. They viewed individual state agency collaboration requirements as too narrow and divergent, while CAC registration guidelines as too broad to cater for state peculiarities. For these reasons, participants assumed that locally constructed frameworks might accommodate these differences, and even new realities regarding the complexity, conduct, scope, and size of the third sector. The outcome, they believed, might be collaborative metagovernance in line with what Asusu frequently described as, "international best practice".

The best practice Asusu, and most government and third sector policy officials who favoured a uniform governing standard talked about was itself not clearly 
defined. Yet participant's views seemed to vary from those like Doka, who suggested enactment of 'juridico-political law' to metagovern collaboration, to actors like $\mathrm{Na}$ Allah who were interested in a less intrusive and more inclusive oriented framework. The problem, Bature cautioned, "Is where government tries to become too stringent." In this case, imposing excessive limitations on the operations of the third sector "will be counterproductive."

Fears of this nature, studies (Ntumba, 2018; Tysiachniouk, Tulaeva, \& Henry, 2018) have shown, run across third sector experiences in most parts of the world, rich as well as poor. Besides, 'best practice' replications or the "blueprint approach" have led to colossal governance failures, as it tends to ignore context peculiarity and local "values, traditions and history" (Bejakovic, 2019: 111).

Part of the reason for this is that state actors use unilaterally constructed governing frameworks to exclude unwanted actors and include surrogates in command positions to ostensibly metagovern collaboration. In some instances third sector actors have been labelled "foreign agents." "That is why we are worried about this uniform coordinating standards thing. They just want to use it to control us and make money for themselves", stated Nadia. Recent experiences of third sector actors in Africa, England and Wales (Kelly, 2019) lend credence to these fears.

Despite these concerns from a few mostly third sector actors, the general view, expressed by Amana, was that, "Getting to know who the genuine third sector actors are was a matter of state responsibility." Therefore the identity of sector members was considered an important component of collaborative frameworks.

On their part, third sector actors were themselves agreed that 'identity' was crucial, but suggested that, "Government fronts in the NGO business are the real problem. They are the bad eggs in the system", said Karkara.

As events transpired, both government and third sector actors were increasingly overwhelmed by anomalies accompanying the dynamic approach. This might explain their seemingly collective demand for proper 'rules of engagement', 'coordination framework', or 'partner coordination forum', suggesting various efforts meant to standardise governing frameworks for successful metagovernance. As Ngai-Ling and Jessop (2019) observed, solidarity has to be restored to its proper place for metagovernance to be truly meaningful. 
As far as the public governance literature is concerned, the imperative of collaboration invites some form of governing standards. Bevir (2013) and McCarthy and Thompson (2020) have argued that governance is rule based and law governed, and metagovernance operates under government's regulatory space. In other words, laws of cross boundary interactions are part of what defines the new governance system and makes it distinct from the conventional government approach to policymaking. Therefore, although the terminologies participants used to describe the 'governing framework' may differ, their common desire seemed to hint at an agreed body of norms to metagovern collaboration. These norms are well articulated in the works of Bejakovic (2019), Meuleman (2019), Holzscheiter, Bahr, and Pantzerhielm (2016) and Sørensen and Torfing (2016).

Another dimension to the stable approach had to do with the proposed contents and modalities for constructing 'coordinating standards'. Government policy actors seemed to favour requirements for collaboration such as, "full financial disclosure" and "income tax", both issues that have triggered worries about state intentions amongst third sector CEOs. For Boko, the important thing was to, "Retrench non-performing NGOs", without penalising the performing ones. This emphasis on performance raised questions around ownership rights (belongingness) versus results, while the focus on fiscal questions suggest the persistence of state control in the metagovernance architecture.

The next stable approach to collaboration is what participants perceived as 'institution building.' This was mainly interpreted to mean setting up a formal agency to be in charge of collaboration. As Adali stated, "You have to put a permanent structure in place, backed by law, so that there will be continuity." This permanent structure was variously described by participants as a "Directorate", "NGO office", "Agency for Third Sector Affairs" or "Donor coordination office."

For the most part, government policy officials claimed that they wanted the coordinating standards to address the following problems: 'Coordination of development partner activities for implementation purpose; Weak capacity of the government to coordinate and harmonize partner activities; Absence of a robust framework to monitor and harmonise partner activities; and Duplication of partner activities in some sectors' (Kano State, 2017). These formal aims represented the government's policy on collaboration through governing standards. But beneath the surface, however, there appeared to be another purpose of the policy: to control, monitor and tax the third sector. 
In fact, the government's formal reason for desiring 'coordination' hinted at this with the words "monitor and harmonise". These expressions might well spell greater state scrutiny and likely trimming down of the third sector. Yet, government actors were keen to point out to us that all they wanted was to ensure, "full transparency and standardisation of counterpart funding arrangements, nothing more", stated Amana. But in reality their decisions have full implications for distribution of benefits, and reflects asymmetry in power relations with the third sector.

At this stage of the discussion, it is necessary to reflect on how the question of governing framework for standardising collaboration relates to the extant governance literature. Part of this reflection was already conveyed in the preceding paragraphs with reference to the works of Ponte, Gibbon, \& Vestergaard (2011), Bevir (2013), and Castelles (2011). The works of Gjaltema, Biesbroek, and Termeer (2019) and Torfing (2019) equally provide useful insights into issues of collaborative governing frameworks, basically subsumed under metagovernance analysis. These works lend weight to the idea that public governance works better under collaborative governing frameworks that serve as platforms for public service innovation, through tapping knowledge, experience, and capacity of diverse actors: government, private, networks, service users, and key influencers.

Perhaps the main point here, which was stressed by Sørensen (2014) but latent in our discussion, is how metagoverning frameworks can be utilised to advance 'public service innovation'. This possibly is what many participants thought of when they used words like "two heads are better than one", and "collaboration brings in new ideas" into the public service.

Therefore, understanding how third sector entities are managed, and how metagovernance can be made effective, is vital to leveraging public service innovation so as to address problems of poverty, fiscal challenges, policy implementation, and declining growth rates (Sørensen, 2014). These development challenges, participants were overwhelmingly convinced, can be better addressed where stable governing standards are applied, making metagovernance not merely relevant in terms of enriching actor collaborative experiences, but fundamental to the overall public governance reform efforts in the state.

For Gjaltema et al. (2019), meta-governance is so central to contemporary governance that future research ought to examine the relationship between 
'metagovernance, democratic legitimacy and governance failure'. The presumption here is not just a causal link between these variables, but one that suggests the possibility of governance failure due to dysfunctionality in how metagoverning frameworks work. This study does not pretend to explore such causal relations. However, it does provide evidence for what prior research on metagovernance already indicates, that 'stakeholder interests', 'shared vision', and 'ad-hoc arrangements' are dynamic, but inadequate approaches to governing collaboration; and that providing 'coordinating standards' is essential to 'institution building' for new governance purposes. Therefore, the absence, or dysfunctionality of such meta-standards, as already implied in the works of Gjaltema risk undermining democratic legitimacy of the third sector in particular, and successful governance in general.

\section{CONCLUSION}

Although the study findings indicate that there was no standard governing framework that guided collaboration between government officials and third sector CEOs, participants seemed to suggest that collaboration was largely governed through pragmatic articulation of 'ad-hoc arrangements', 'shared vision' and 'stakeholder interests.' This dynamic approach was considered unstable by an overwhelming number of participants. This instability, however, was to be resolved through the introduction of 'partner coordinating standards' by government policy officials. Yet, this effort was considered too dependent on foreign 'partner' support, and alienating to weaker local third sector actors. In the light of this, it was perceived by a few third sector CEOs as both defective and dubious.

However, participants' comments largely reveal a preference for the coconstruction of a standard governing framework that will ensure project sustainability, full disclosure of partner accounts, accountable data management, resolution of data ownership rights, and inclusive stakeholder interests in the state. This approach, it would appear, is likely to provide the basis for creatively merging the relevant resilient features of the dynamic and the stable governance frameworks to produce an innovative metagovernance system. As the evidence suggest, public service innovation in policy articulation and service delivery are interlinked with how metagovernance is conducted. This, we presume, might provide the basis for lasting metagovernance and democratic legitimacy for the third sector in Kano state. 
Therefore, the preferred option for successful metagovernance of collaboration might be a cross between the dynamic framework approach with its flexibility and innovation, on the one hand, and the stable framework approach with its regularity, predictability, and strategic advantage, on the other. Amalgamated, this innovative governance framework might be a vehicle for dehomogenising the public service, removing its mental silos, and making it more culturally sensitive, developmentally focused and change oriented.

We realise however that the mere design of a governance framework will not guarantee the full application of metagovernance. Environmental and context specific factors will have to be taken into account. But as governance systems across the world come under pressure as a result of rapid changes in multiple spheres of life: climate change, the economy, mass migration, biotechnology, artificial intelligence, quantum computing, pandemics, and security sector reengineering, there seems to be the realisation amongst citizens groups and state actors alike that new governing standards anchored on shared vision, stakeholder interests, pragmatic arrangements, resilience, reflexivity, inclusivity, and critical self-evaluation, have to be co-created and co-produced for the common good if new public governance is to deliver sustainable development. This, we presume, underscores the centrality of boundary spanning, governance standards and metagovernance systems, not just in the developing world but, in the developed countries as well.

\section{REFERENCES}

Abbas, T., \& Hamid, S. (Eds.). (2019). Political Muslims: Understanding youth resistance in a global context. Syracuse: Syracuse University Press.

Ali, A., \& Ghazali, S. (2020). The third sector in public governance in Nigeria: Concept, identity and Prospects. Journal of Public Administration and Governance, 10(1): 298-311. doi:http://dx.doi.org/10.5296/jpag. v10i1.16407

Bang, H. (2014). Foucault's political challenge: Where there is obedience there cannot be parrhesia. Administrative Theory \& Praxis, 36(2): 175-196.

Beckman, B. (2010). Changing government: Alliance politics in Nigeria's civil society. In The Author, Power to the People? (con-)tested civil society in search of democracy. Uppsala: Uppsala Centre for 
Sustainable Development.

Bejakovic, P. (2019). Louis Meuleman: Metagovernance for sustainability: A framework for implementing the sustainable development goals. Public SectorEconomics, 43(1): 109- 113. doi:https://doi.org/10.3326/ pse.43.1.7

Bevir, M. (2013). Governance as theory, practice, and dilemma. In M. Bevir (Ed.), The Sage Handbook of Governance (pp. 1-16). London: Sage. Brandsen, T., Steen, T., \& Verschuere, B. Eds. (2018). Co-production and co-creation: Engaging citizens in public services. New York: Routledge.

Brinkman, S. \& Kvale, S. (2018). Doing interviews. London: Sage.

Burchell, G., Gordon, C., \& Miller, P. (1991). The Foucault effect: Studies in governmentality. Chicago: University of Chicago.

Castells, M. (2011). A network theory of power. International Journal of Communication, 5: 773-789. Retrieved from http://ijoc.org

Castells, M. (2007). Communication, power and counter-power in the network society. International Journal of Communication, 1: 238266. doi:https://doi.org/10.1080/14719037.2019.1648697

Grbich, C. (2013). Qualitative data analysis: An introduction (2nd ed.). London: Sage.

Holzscheiter, A., Bahr, T., \& Pantzerhielm, L. (2016). Emerging Governance Architectures in Global Health: Do Metagovernance Norms Explain Inter-Organisational Convergence? Politics and Governance, 4 (3): 5-19. doi: 10.17645/pag.v4i3.566

Howitt, D., \& Cramer, D. (2016). Introduction to qualitative research methods in psychology (3rd ed.). London: Pearson.

International Center for Not-For-Profit Law (ICNL), Nigeria (2020). Update, 19 March 2020. Retrieved from https://www.icnl.org/resources/civicfreedom-monitor/nigeria

International Labour Organisation (ILO). (2011). Manual on the measurement of volunteer work. Geneva: International Labour Office.

Jessop, B. (2007 $)$. The regulation approach. In M. Bevir (Ed.), Public Governance vol. 1: Theories of Governance. Lindon: Sage. Pp. 190229.

Jessop, B. (2007 $)$. Governance and meta-governance: On reflexivity, requisite variety and requisite irony. In M. Bevir (Ed.), Public Governance vol. 1: Theories of Governance. Lindon: Sage. Pp. 230-245.

Kano State Ministry of Planning and Budget. (2017). Draft: Review and recommendations for a donor coordination framework in Kano state (Report June 23, 2017). Kano: Author. 
Kelly, L. (2019). Legislation on non-governmental organisations (NGOs) in Tanzania, Kenya, Uganda, Ethiopia, Rwanda and England and Wales. K4D Helpdesk Report. Brighton, UK: Institute of Development Studies.

Koliba, C., Meek, J. W., \& Zia, A. (2011). Governance networks in public administration and public policy. London: CRC Press.

Kukah, M. H. (2013). Civil society: Theory and practice. In O. Akinkugbe and A. Joda (Eds.),Olusegun Obasanjo: The Presidential Legacy 1999-2007 vol. 2. Ibadan: Bookcraft.

Kukah, M. H. (2001). Democracy and civil society in Nigeria. Ibadan: Spectrum.

Lash, S. (2002). Forward: Individualization in non-linear mode. In U. Beck and E. Beck-Gernsheim (Eds.), Individualization: Institutionalized individualism and its social and political consequences. London: Sage. Pp. vii-xiii. doi: http://dx.doi.org/10.4135/9781446218693

Marewll, N. P., \& Brown, M. (2020). Towards a governance framework for government- nonprofit relations. In W. W. Powell \& P. Bromley (Eds.), The Nonprofit Sector: A research Handbook (3 ${ }^{\text {rd }}$ ed.). Stanford: Stanford University Press. Retrieved from https://books.google.com. my> publication

Marsh, D. (2011). The new orthodoxy: The differentiated policy model. Public Administration, 89(1): 32-48.

Mazrui, A. A. (2012). Nigeria: from shari'a movement to "Boko Haram." [Draft paper] (Written for Global Experts Team, United Nations' Alliance of Civilizations, June 2012).

Mazrui, A. A. (1986). The Africans: A triple heritage. London: Little Brown.

McCarthy, S. \& Thompson, M. R. (2020). Governance and democracy in the Asia-Pacific; Political and civil society. New York: Routledge.

McKeever, B. S. (2018/2019). The nonprofit sector in brief 2019: Public charities, giving, and

volunteering. National Center for Charitable Statistics, 3 January 2019. Retrieved from https://nccs.urban.org $>$ project $>$ nonpro.

Merriam, S. B. \& Grenier, R. S. (2019). Qualitative research in practice: Examples for discussion and analysis (2nd ed.). San Francisco: Jossey-Bass.

Meuleman, L. (2019). Metagovernance for sustainability: A framework for implementing the sustainable development goals. Oxon/New York: Routledge. doi: https://doi.org/10.4332/9781351250603 
Meuleman, L. (2008). Public management and the metagovernance of hierarchies, networks and markets: The feasibility of designing and managing governance style combinations. The Hague: PhysicaVerlag.

Milward, H. B. (2015). The state and public administration: Have instruments of governance outrun governments? Introductory perspectives. Asia Pacific Journal of Public Administration, 37(5): 217-223.

Nega, B. \& Schneider, G. (2014). NGOs, the state, and development in Africa. Review of Social Economy, 72(4): 458-503. doi: https://doi.o $\mathrm{rg} / 10.1080 / 00346764.2014 .958901$

Ngai-Ling, S. \& Jessop, B. (2019). Putting solidarity in its place in metagovernance. In P. Van den Broeck, A. Mehmood, A. Paidakaki \& C. Parra(Eds.), Social Innovation as Political Transformation: Thoughts for a Better World. doi: https://doi.org/10.4337/9781788974288. Pp. 90-96.

Nigeria Network of NGOs (NNNGO). (2020). Press Release: House of Representatives Rejects Civil Society Bill. Retrieved from https:// nnngo.org/4105-2

Ntumba, P. N. (2018). Case study - Co-creation and empowerment: the case of DR Congo in agricultural and rural sector. In T. Brandsen, T. Steen, $\&$ B. Verschuere (Eds.), Co-production and co-creation: Engaging citizens in public services. New York: Routledge. Pp. 240-242.

Pedersen, A., Sehested, K., \& Sørensen, E. (2011). Emerging theoretical understandings of pluricentric coordination in public governance. American Review of Public Administration, 41(4): 375-394.

Ponte, S., Gibbon, P., \& Vestergaard, J. (Eds.).(2011). Governing through standards: Origins, drivers and limitations. UK: Palgrave Macmillan.

Raffnsqe, S., Gudmand-Hoyer,M., \& Thaning, M. S. (2016). Michel Foucault: A research companion. England: Palgrave Macmillan.

Rose, N. (1996) Governing "advanced" liberal democracies. In A. Barry, T. Osborne and N. Rose (eds.), Foucault and Political Reason: Liberalism, Neoliberalism and Rationalities of Government. Chicago: University of Chicago Press. Pp. 37-64.

Ruby, T. F. (2019). Muslim women's rights: Contesting liberal-secular sensibilities in Canada. London: Routledge. doi: https://doi. org/10.4324/9781315182933

Salamon, L. M., Sokolowski, S. W., Haddock, M. A., \& Tice, H. S. (2013). The state of civil society volunteering: Latest findings from the implementation of the UN nonprofit handbook. Baltimore: Johns Hopkins University. 
Smith, D. J. (2012). AIDS NGOs and corruption in Nigeria. Health Place, 18(3): 475-480. doi:10.1016/j.healthplace.2011.11.002.

Smith, D. J. (2010). Corruption, NGOs, and development in Nigeria. Third World Quarterly, 31(2): 243-258.

Sørensen, E. (2014). The metagovernance of public innovation in governance networks (Paper to be presented at the Policy \& Politics conference in Bristol, 16-17 of September 2014). Retrieved from https://www. bristol.ac.uk $>$ migrated

Sørensen, E., \& Torfing, J. (2016). Metagoverning collaborative innovation in governance networks. The American Review of Public Administration. doi: https://doi.org/10.1177/0275074016643181

Sørensen, E., \& Torfing, J. (2007). Theoretical Approaches to Metagovernance. The Authors (Eds.), Theories of Democratic Network Governance. New York: Palgrave Macmillan. Pp. 169-181.

Torfing, J. (2019). Collaborative innovation in the public sector: The argument, Public Management Review, 21(1):1-11.

Tysiachniouk, M., Tulaeva, S., \& Henry, L. A. (2018). Civil society under the law 'On Foreign Agents': NGO strategies and network transformation. Europe-Asia Studies, 70(4): 615-637. doi: 10.1080/0966813.1463512.

United Nations. (2018). Satellite account on non-profit and related institutions and volunteer work. New York: Department of Economic and Social Affairs.

Usman, Y. B. (2008). Nation-states and the future of mankind: Some observations on the historical experience of the formation of the Kanawa in the $2^{\text {nd }}$ Millennium A.D. In Abdullahi Smith Centre (Ed.), Beyond fairy tales: Selected historical writings of Yusufu Bala Usman Vol. 1. Zaria: Abdullahi Smith Centre for Historical Research. Pp. 143-158. 